68

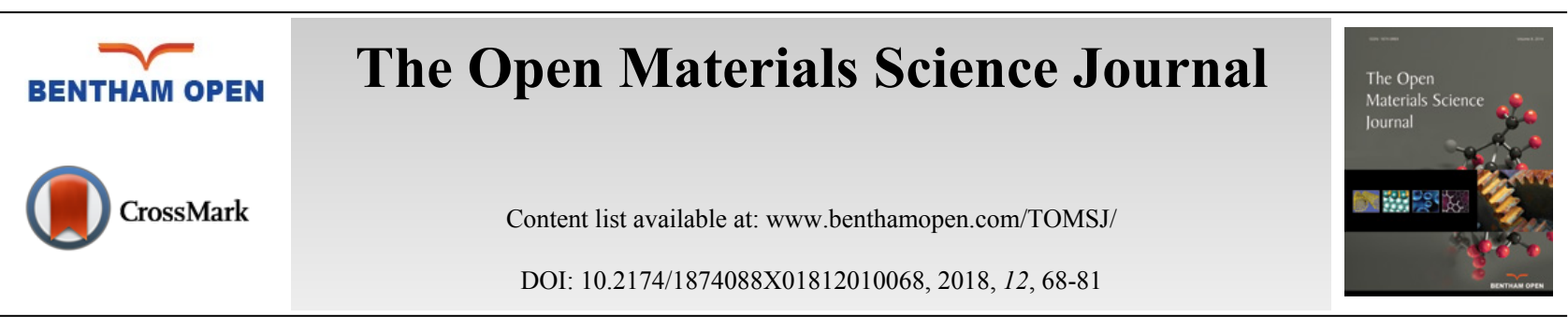

RESEARCH ARTICLE

\title{
Corrosion Inhibition of Mild Steel in 1.0 M HCl Solution by Anhydrous Tricalcium Phosphate
}

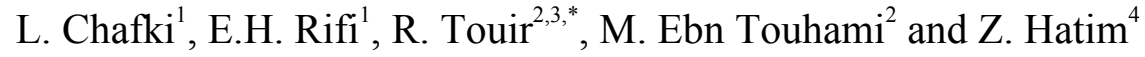 \\ ${ }^{1}$ Laboratory of Organic Synthesis and Process d'Extraction, Faculty of Science, University Ibn Tofail, Kenitra, \\ Morocco \\ ${ }^{2}$ Laboratory of Materials Engineering and Environment: Modeling and Application, Faculty of Science, University Ibn \\ Tofail BP. 133-14000, Kenitra, Morocco \\ ${ }^{3}$ Centre Régional des Métiers de l'Education et de la Formation (CRMEF), Avenue Allal Al Fassi, Madinat Al Irfane, \\ BP 6210 Rabat, Morocco \\ ${ }^{4}$ Laboratory of Electrochemistry and Surface Treatment, Faculty of Sciences, El Jadida, Morocco
}

Received: April 25, 2018

Revised: June 13, 2018

Accepted: June 20, 2018

\section{Abstract:}

Objective:

In this study, electrochemical measurements were used to characterize Anhydrous Tricalcium Phosphate (ATP) as a corrosion inhibitor for mild steel in $1.0 \mathrm{M} \mathrm{HCl}$.

\section{Method:}

The potentiodynamic polarization curves indicated that the ATP reacts as an anodic type inhibitor. In addition, it has been found that the electrochemical impedance confirms the inhibitor character of ATP obtained by the potentiodynamic polarization curves where the inhibition efficiency increases by its concentration to reach a maximum of $93.79 \%$ at $10^{-4} \mathrm{M}$. The temperature solution influence indicated that the corrosion rate increases with temperature while the inhibitor acts actively. Thermodynamic adsorption and activation parameters indicated that the ATP acts by physical adsorption on the metallic surface with an endothermic process of metal dissolution.

Result:

Additionally, it was found that the adsorption of ATP molecules obeyed to the Langmuir isotherm. Surface analyses via scanning electron microscopy (SEM) was used to investigate the morphology of mild steel before and after immersion in $1.0 \mathrm{M} \mathrm{HCl} \mathrm{solution}$ without and with $10^{-4} \mathrm{M}$ of ATP. It is revealed that the ATP acted by the formation of a protective layer on the mild steel.

Keywords: Anhydrous tricalcium phosphate, Corrosion inhibition, Mild steel, Hydrochlorid acid, Electrochemical measurements, SEM analysis.

\section{INTRODUCTION}

Acid solutions are widely used to eliminate unwanted rust in metalworking, cleaning boilers and heat exchangers. So, the highly corrosive nature of $\mathrm{HCl}$ must be controlled by a suitable corrosion inhibitor [1 - 4]. According to the literature, the best inhibitors which can be adsorbed on the metallic surface contain in their structures heteroatoms such as oxygen, nitrogen, phosphorus and/or triple bonds [5 - 8].

* Address for correspondence to this auther at the Laboratory of Materials Engineering and Environment: Modeling and Application, Faculty of Science, University Ibn Tofail BP. 133-14000, Kenitra, Morocco, E-mails: touir8@yahoo.fr; touir8@gmail.com 
However, in the literature, many phosphate derivatives have been investigated as corrosion inhibitors and it has been found that they are excellent corrosion inhibitors $[9,10]$. It is found that these compounds act as mixed type inhibitors and their performances increase with immersion time. Thus, the inhibition property of the phosphocalcic compounds is certified to their pairs and planarity of free electrons in oxygen and phosphorus. On the other hand, the anhydrous tricalcium phosphate derivatives are considered as non-toxic substances. With respect to the environment, the Anhydrous Tricalcium Phosphate (ATP) is favorable to be used in place of some toxic organic inhibitors in agreement with the new environmental limits [11,12]. Additionally, the force of its adsorbed layer on metallic surface, according to the Langmuir isotherm, was associated to the functional groups of the aromatic ring [13].

However, the adsorption of organic compounds depends specially on their electronic structure where their inhibition efficiencies increase with the number of aromatic rings [14, 15]. Finally, the adsorption of these molecules on the metallic surface is linked to their molecular structure, zero charge potential of metals and surface charge density [16].

The principal objective of this study was to examine the influence of inhibition of ATP molecule on mild steel corrosion in $1.0 \mathrm{M} \mathrm{HCl}$ using potentiodynamic polarization measurements and electrochemical impedance spectroscopy coupled with Scanning Electron Microscope (SEM) analysis. The effect of temperature and immersion time on the performance of ATP was also studied

\section{MATERIALS AND METHODS}

\subsection{Material and Compound}

The tested inhibitor is the calcium phosphate carrier named anhydrous tricalcium phosphate (ATP) and its molecular formula and projection on the plane are shown in (Fig. 1).

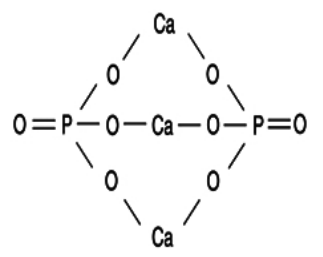

Fig. (1). Projection on the plane of the ATP structure.

\subsection{Electrochemical, Cell aqnd Electrodes}

Table 1 illustrates the chemical composition of the used mild steel. Before each experiment, this electrode was prepared like as our previous works [3 - 6]. The corrosive electrolyte was $1.0 \mathrm{M} \mathrm{HCl}$ and the concentration of the tested ATP was in the range from $10^{-6} \mathrm{M}$ to $10^{-3} \mathrm{M}$.

Table 1. Chemical composition of the working electrode.

\begin{tabular}{|c|c|c|c|c|c|c|c|c|c|c|c|}
\hline $\mathbf{C}$ & $\mathbf{S i}$ & $\mathbf{M n}$ & $\mathbf{C r}$ & $\mathbf{M o}$ & $\mathbf{N i}$ & $\mathbf{A l}$ & $\mathbf{C u}$ & $\mathbf{C o}$ & $\mathbf{V}$ & $\mathbf{W}$ & $\mathbf{F e}$ \\
\hline 0.11 & 0.24 & 0.47 & 0.12 & 0.02 & 0.1 & 0.03 & 0.14 & $<0.0012$ & $<0.003$ & 0.06 & Balance \\
\hline
\end{tabular}

However, the current intensity - potential curves were recorded by scanning the electrode from the open circuit potential $\left(\mathrm{E}_{\mathrm{OCP}}\right)$ to the negative values and from $\mathrm{E}_{\mathrm{OCP}}$ to the positive values by using a Potentiostat/Galvanostat PGZ 100 with a scan rate equal to $1 \mathrm{mV} / \mathrm{s}$ after 30 minutes of immersion at $298 \mathrm{~K}$. Ag/AgCl and platinum grid were used as the reference and auxiliary electrodes, respectively.

The electrochemical data were determined by the Tafel lines extrapolation and the inhibition efficiency was obtained as follows:

$$
\eta_{\mathrm{pp}}=\frac{i_{\text {corr }}^{0}-i_{\text {corr }}}{i_{\text {corr }}^{0}} \times 100
$$

where $\mathrm{i}^{0}{ }_{\text {corr }}$ and $\mathrm{i}_{\text {corr }}$ are the corrosion current densities values without and with ATP at different concentrations, respectively.

In addition, the Electrochemical Impedance Spectroscopies (EIS) were carried out with $10 \mathrm{mV}$ rms from $100 \mathrm{kHz}$ to $100 \mathrm{mHz}$ of frequencies with ten points/decade. The obtained plots were analyzed using the Z-Veiw program and the 
inhibition efficiency was calculated as follows:

$$
\eta_{\mathrm{SIE}}=\frac{\mathrm{R}_{\mathrm{ct}}-\mathrm{R}_{\mathrm{ct}}^{0}}{\mathrm{R}_{\mathrm{ct}}} \times 100
$$

where $\mathrm{R}_{\mathrm{ct}}{ }^{0}$ and $\mathrm{R}_{\mathrm{ct}}$ are the charge transfer resistance values without and with ATP at different concentrations, respectively.

\subsection{Scanning Electron Microscope Characterization}

The morphology of the sample surface before and after being treated with optimal concentration of ATP was examined by Scanning Electron Microscope (SEM) JEOL JSM-IT 100.

\section{RESULTS AND DISCUSSION}

\subsection{Potentiodynamic Polarization Curves}

\subsubsection{Open Circuit Potential}

Fig. (2) illustrates the variation in open circuit potential $\left(\mathrm{E}_{\mathrm{OCP}}\right)$ with time without and with different concentrations of ATP. It was observed that the potential for uninhibited solution decreases with time and stabilizes at the value of $496 \mathrm{mV} / \mathrm{Ag} / \mathrm{AgCl}$ after 30 minutes. This phenomenon can be explained by the degradation of mild steel with a formation of corrosives products on its surface. So, in the presence of ATP, the potential shifts in the anodic direction become (ennobling of potential) quickly stable with time. This phenomenon can be explained by the formation of a protective film on the metallic surface.

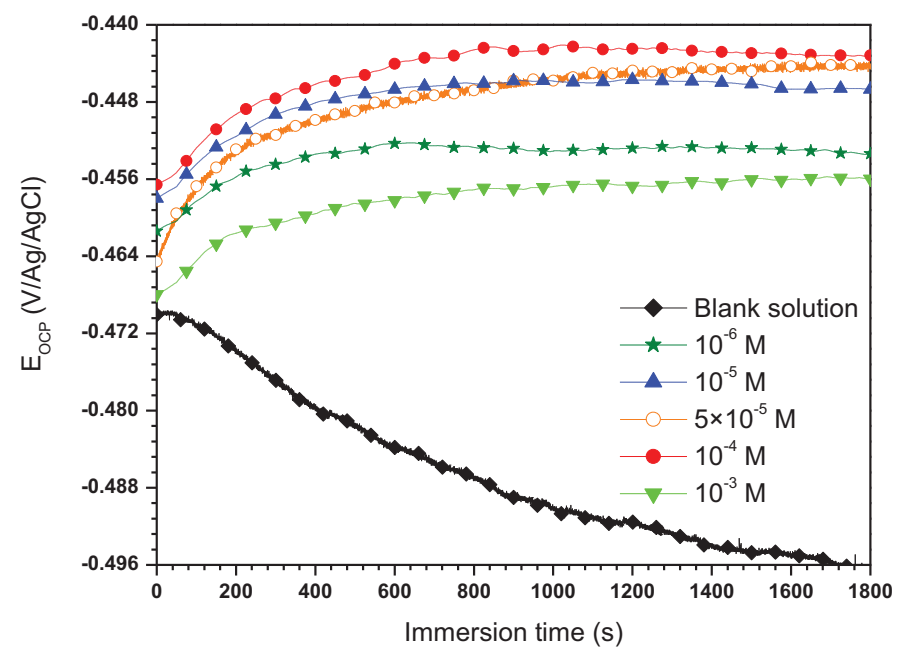

Fig. (2). Evolution of $\mathrm{E}_{\mathrm{OCP}}$ versus time for mild steel in $1.0 \mathrm{HCl}$ without and with different concentrations of ATP.

\subsubsection{Potentiodynamic Polarization Curves}

The current intensity potential curves for mild steel in $1.0 \mathrm{M} \mathrm{HCl}$ solution containing different concentrations of ATP are illustrated in Fig. (3) and their corresponding electrochemical data are presented in Table 2. From these curves, it can be observed that the current density decreases with ATP concentrations indicating its adsorption on the metallic surface which inhibits the effect of aggressive ions. These finding suggested that this inhibitor behaves as a mixed type inhibitor. In addition, it is can be observed clearly that the cathodic currents reduce with ATP addition indicating that the hydrogen reduction reaction is inhibited [17]. This result indicated also that the energy barrier for proton discharge increases causing a decrease in the gas evolution quantity [18]. It is remarked also in the anodic range that a pseudo plate appeared especially at $10^{-4} \mathrm{M}$ of ATP. On the other hand, it has been noted that the anodic Tafel slope $\left(\beta_{\mathrm{a}}\right)$ values in the presence of ATP were approximately constant indicating no change in the anodic oxidation mechanism where the ATP was adsorbed firstly onto the metallic surface and blocked the reaction sites [19]. 
Table 2. Electrochemical parameters for mild steel in 1.0 M HCl containing different concentrations of ATP at $298 \mathrm{~K}$.

\begin{tabular}{|l|c|c|c|c|c|c|c|}
\hline & $\mathbf{C}(\mathbf{M})$ & $\mathbf{E}_{\text {corr }}(\mathbf{m V} / \mathbf{A g} / \mathbf{A g C I})$ & $\mathbf{i}_{\text {corr }}\left(\boldsymbol{\mu A} / \mathbf{c m}^{2}\right)$ & $\boldsymbol{\beta}_{\mathbf{a}}(\mathbf{m V} / \mathbf{d e c})$ & $\boldsymbol{\beta}_{\mathbf{c}}(\mathbf{m V} / \mathbf{d e c})$ & $\boldsymbol{\theta}$ & $\boldsymbol{\eta}_{\mathbf{p p}}(\mathbf{\%})$ \\
\hline \multirow{3}{*}{ Blank solution } & 00 & -498 & 467 & 70 & -153 & - & - \\
\hline \multirow{4}{*}{ ATP } & $10^{-6}$ & -427 & 50 & 79 & -110 & 0.8929 & 89.29 \\
\cline { 2 - 9 } & $10^{-5}$ & -427 & 48 & 82 & -105 & 0.8972 & 89.72 \\
\cline { 2 - 9 } & $5 \times 10^{-5}$ & -466 & 35 & 75 & -90 & 0.9250 & 92.50 \\
\cline { 2 - 9 } & $10^{-4}$ & -422 & 28 & 87 & -106 & 0.9400 & 94.00 \\
\cline { 2 - 9 } & $10^{-3}$ & -429 & 52 & 71 & -107 & 0.8886 & 88.86 \\
\hline
\end{tabular}

In addition, from Table 2, the shift of the corrosion potential $\mathrm{E}_{\text {corr }}$ to the positive direction with ATP addition confirmed its anodic type character. Consequently, the tested ATP is effective at the small concentration where its inhibition efficiency reached $94 \%$ at $10^{-4} \mathrm{M}$. After this critical concentration, the inhibition effect of ATP decreased. This suggests the formation of soluble ATP complex [20].

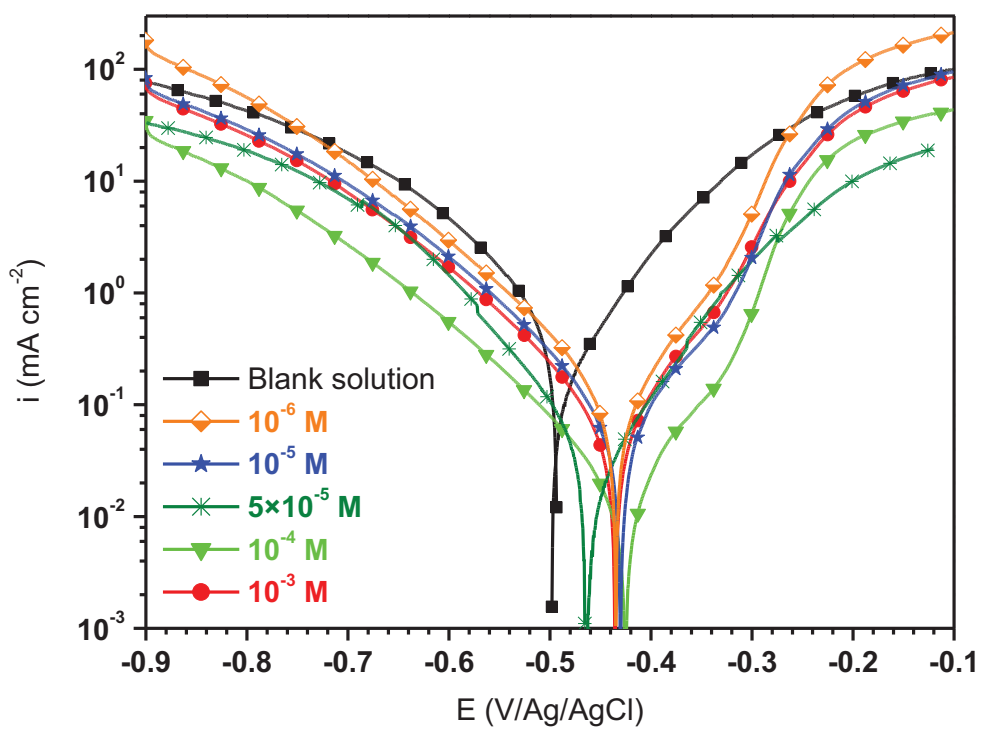

Fig. (3). Polarization curves for mild steel in $1.0 \mathrm{M} \mathrm{HCl}$ containing different concentrations of ATP.

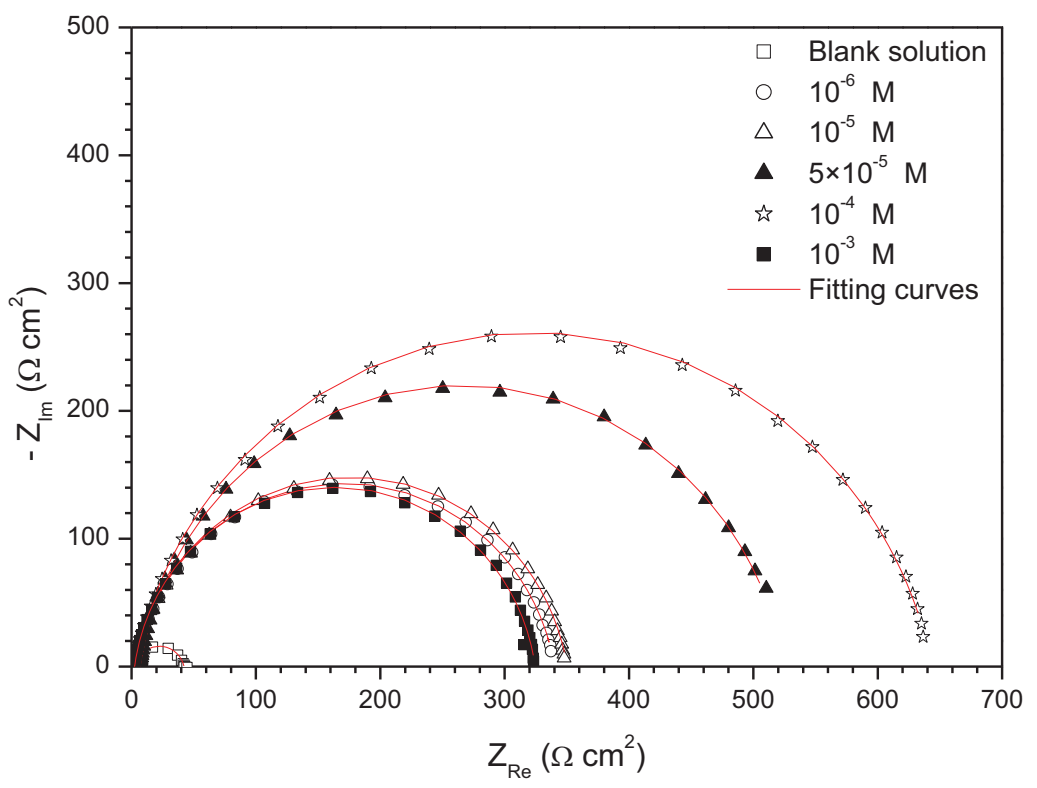

Fig. (4). Nyquist plots for mild steel in $1.0 \mathrm{M} \mathrm{HCl}$ without and with different concentrations of ATP at EOCP $(\mathrm{T}=298 \mathrm{~K})$. 


\subsection{Electrochemical Impedance Spectroscopy}

The electrochemical impedance spectroscopy diagrams of mild steel in $1.0 \mathrm{M} \mathrm{HCl}$ containing different concentrations of ATP after 30 min of immersion at $\mathrm{E}_{\mathrm{OCP}}$ and at $298 \mathrm{~K}$ are presented in Fig. (4). It is observed that all diagrams were composed of one capacitive loop. In this case, the equivalent electric circuit presented in Fig. (5), with one time constants, was proposed to extract and module interface metal/solution.

It is well-known that the application of the double layer capacitor does not always facilitate achieving satisfactory experimental impedance data. So, the dispersion of the impedance data can be due to the heterogeneity of the surface. In this case, the Constant Phase Element (CPE) was suggested where its impedance can be given as follows:

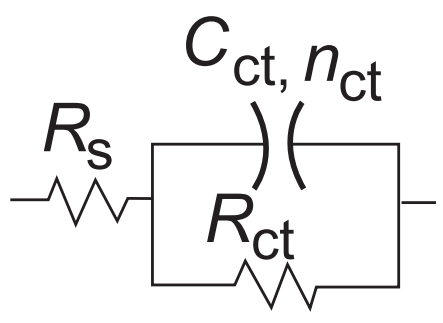

Fig. (5). Electrical equivalent circuit used for modeling the metal/solution interface.

$$
\mathrm{Z}_{\mathrm{CPE}}=\left[Q(\mathrm{j} \omega)^{-\mathrm{n}}\right]^{-1}
$$

where $\mathrm{j}, \mathrm{Q}$, and $\omega$ are the imaginary number, the frequency independent real constant and the angular frequency, respectively. Indeed, the $\mathrm{n}$ is the CPE exponent for the whole number of $\mathrm{n}=1,0,-1, \mathrm{CPE}$ is reduced to the classical lump element-capacitor (C), resistance (R) and inductance (L), respectively [21]. However, the effective double layer capacitance (C) was calculated as follows [22]:

$$
\mathrm{C}_{\mathrm{dl}}=\left(\mathrm{Q}_{\mathrm{dl}} \mathrm{R}_{\mathrm{ct}}^{1-\mathrm{n}}\right)^{1 / \mathrm{n}}
$$

The most important data obtained using the proposed equivalent circuit are offered in Table 3. It can be remarked that $\mathrm{R}_{\mathrm{ct}}$ values increase while $\mathrm{C}_{\mathrm{dl}}$ values decrease with ATP concentrations indicating its adsorption on the metallic surface providing better surface coverage [23, 24].

Table 3. Electrochemical parameters associated to the impedance diagrams for mild steel in 1.0 M HCl at different concentrations of ATP at $E_{O C P}$ and at $298 \mathrm{~K}$.

\begin{tabular}{|c|c|c|c|c|c|c|c|}
\hline- & $\mathbf{C}(\mathbf{M})$ & $\mathbf{R}_{\mathbf{s}}\left(\mathbf{\Omega} \mathbf{~ c m}^{2}\right)$ & $\mathbf{R}_{\mathrm{ct}}\left(\mathbf{\Omega} \mathbf{~ c m}^{\mathbf{2}}\right)$ & $\mathbf{C}_{\mathrm{dl}}\left(\boldsymbol{\mu} \mathbf{F} \mathbf{c m}^{-2}\right)$ & $\mathbf{n}_{\mathrm{ct}}$ & $\boldsymbol{\tau}_{\text {dl }}(\mathbf{m s})$ & $\boldsymbol{\eta}_{\mathrm{EIS}}(\mathbf{\%})$ \\
\hline Blank Solution & 00 & $2.35 \pm 0.42$ & $39.85 \pm 0.74$ & $139.24 \pm 5.38$ & $0.85 \pm 0.01$ & $5.55 \pm 0.003$ & - \\
\hline \multirow{4}{*}{ ATP } & $10^{-6}$ & $2.34 \pm 0.19$ & $337.6 \pm 0.33$ & $118.71 \pm 3.17$ & $0.87 \pm 0.01$ & $40.07 \pm 0.001$ & 88.19 \\
\cline { 2 - 9 } & $10^{-5}$ & $2.39 \pm 0.19$ & $347.80 \pm 0.42$ & $111.88 \pm 1.00$ & $0.89 \pm 0.01$ & $38.41 \pm 0.001$ & 88.54 \\
\cline { 2 - 8 } & $5 \times 10^{-5}$ & $6.81 \pm 0.21$ & $517.9 \pm 0.78$ & $86.25 \pm 1.17$ & $0.90 \pm 0.01$ & $44.67 \pm 0.001$ & 92.30 \\
\cline { 2 - 8 } & $10^{-4}$ & $2.03 \pm 0.19$ & $642.00 \pm 0.28$ & $45.04 \pm 0.68$ & $0.91 \pm 0.01$ & $28.91 \pm 0.001$ & 93.79 \\
\cline { 2 - 8 } & $10^{-3}$ & $2.43 \pm 0.20$ & $322.00 \pm 0.42$ & $71.38 \pm 1.78$ & $0.89 \pm 0.01$ & $22.98 \pm 0.001$ & 87.62 \\
\hline
\end{tabular}

In addition, it is shown that the $n$ values increase with inhibitor concentration, which could be related to the decrease of the surface heterogeneity as a result of the ATP molecules' adsorption on mild steel surface and formation of a uniform inhibitive film. In the same way, the relaxation time constant $\left(\tau_{\mathrm{dl}}=\mathrm{R}_{\mathrm{ct}} \times \mathrm{C}_{\mathrm{dl}}\right)$ values increase with ATP addition as well and the time of adsorption process becomes therefore much longer which means a slow adsorption process [25]. This shows that there is an agreement between the charge amount stored in capacitance and discharge velocity in the interface metal/solution $\left(\tau_{\mathrm{dl}}\right)[26]$.

On the other hand, a good agreement between the inhibition efficiencies values obtained from the impedance 
spectroscopy and polarization curve was obtained, indicating that the corrosion rate does not depend on the applied technique [27].

\subsection{Temperature Solution Effect}

\subsubsection{Potentiodynamic Polarization Curves}

The study of the influence of temperature solution on the corrosion rate of mild steel in $1.0 \mathrm{M} \mathrm{HCl}$ without and with $10^{-4} \mathrm{M}$ of ATP was investigated using potentiodynamic polarization and the obtained curves are shown in Fig. (6 and 7), respectively. It is observed that the augment in the temperature increases the corrosion current density a little in both cases. It is also remarked that the increase in temperature displaces the $\mathrm{E}_{\text {corr }}$ to the anodic and cathodic directions in the absence and presence of ATP, respectively. As a result, the inhibition efficiency of ATP depends on the temperature solution which decreases with its increase. According to the literature, at the lower temperatures, the inhibitor was physically adsorbed while at the high temperature, it was chemisorbed [28].

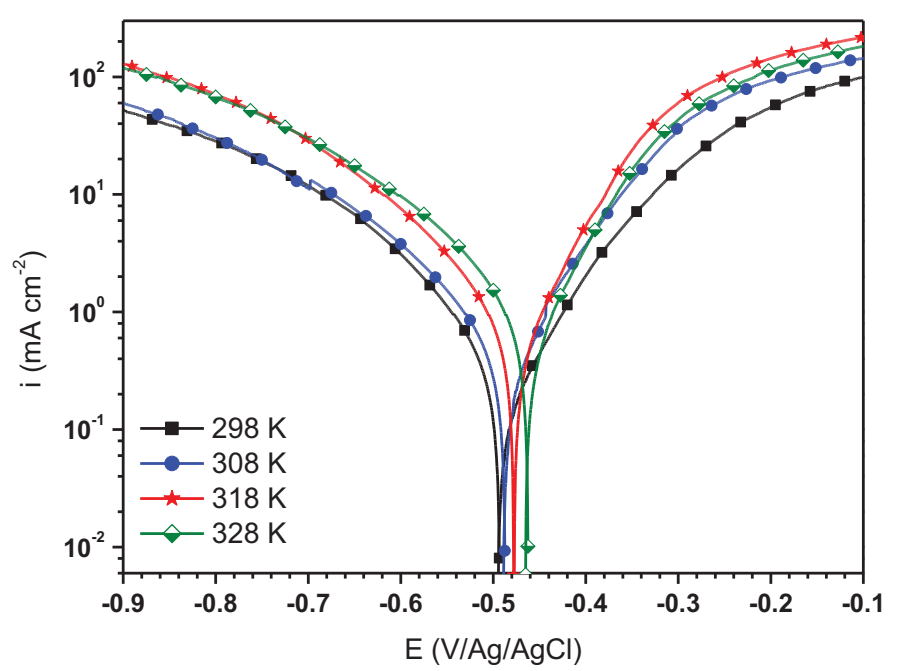

Fig. (6). Potentiodynamic polarization curves for mild steel in uninhibited solution at different temperatures.

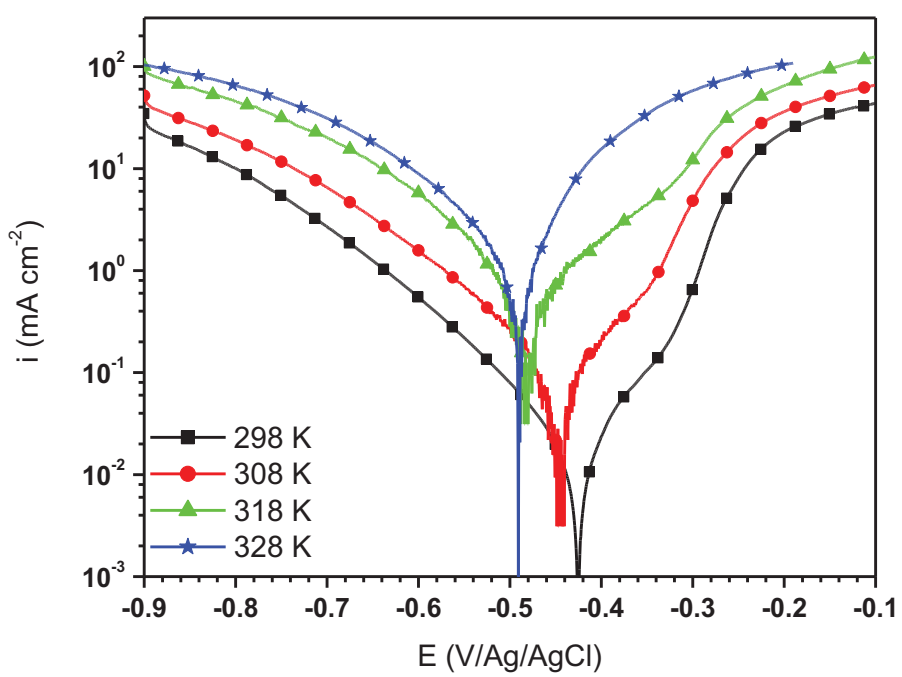

Fig. (7). Potentiodynamic polarization curves for mild steel in $1.0 \mathrm{M} \mathrm{HCl}$ containing $10-{ }^{4} \mathrm{M}$ of ATP at different temperatures.

\subsubsection{Kinetic Parameters of Activation Corrosion Process}

Generally, the temperature influences the inhibition reactions, because of many changes that take place on the metal surface such as adsorption and desorption of inhibitor molecules. So, the variation $i_{\text {corr }}$ with $1 / T$ for mild steel electrode in $1.0 \mathrm{M} \mathrm{HCl}$ without and with different concentrations of ATP was investigated and the obtained linear plots using Arrhenius equation (5) [29] are presented in (Fig. 8). 


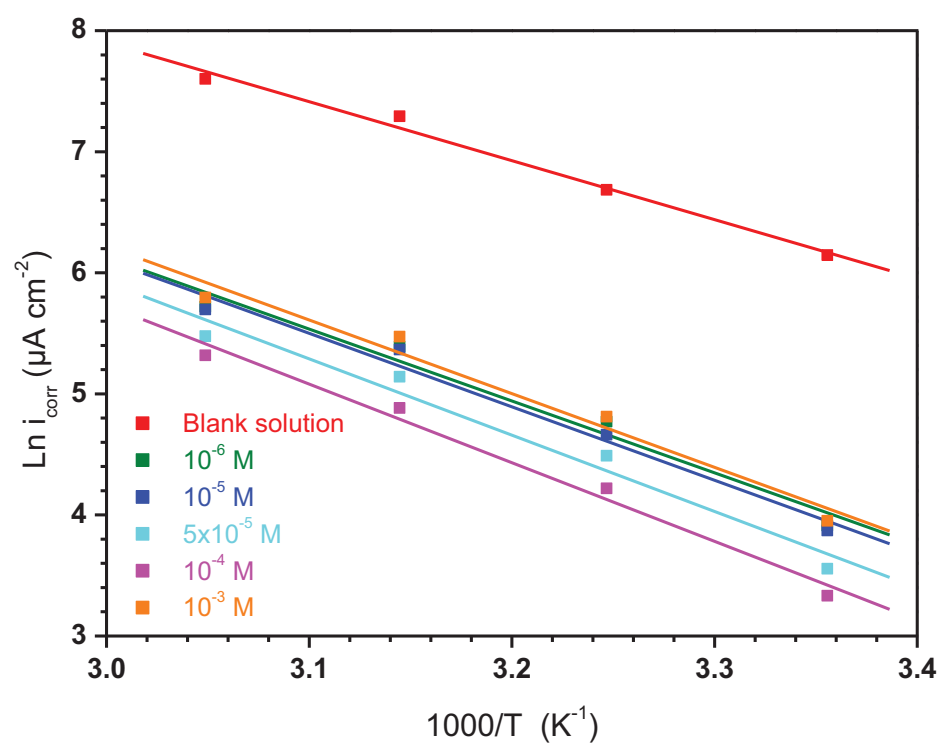

Fig. (8). Arrhenius plots for mild steel in $1.0 \mathrm{M} \mathrm{HCl}$ solution without and with of different concentrations of ATP.

$$
i_{\text {corr }}=K \times \exp \left(\frac{-E_{a}}{R T}\right)
$$

where $E_{a}, K, R$ and $T$ represent the energy of activation, the pre-exponential factor, the universal gas constant and the absolute temperature, respectively and the obtained values of the kinetic parameters are illustrated in Table $\mathbf{5}$. It was found that the values of the correlation coefficients of all the linear regression are close to 1 , signifying that the mild steel dissolution can be explained using Arrhenius model. It can be noted from Table 5, that the $\mathrm{E}_{\mathrm{a}}$ increases with increasing ATP concentrations. It is also remarked that all values of $\mathrm{E}_{\mathrm{a}}$ in the studied range of concentration, are higher than that of the uninhibited solution. This increase in the $\mathrm{E}_{\mathrm{a}}$ in the presence of ATP may be interpreted by its physical adsorption on the metallic surface. Effectively, a higher energy barrier for the corrosion process in the inhibited solution was involved with physical adsorption or feeble chemical bonding in the midst of the inhibitors nature and the steel surface [30]. Szauer et al., indicated that the augment in $\mathrm{E}_{\mathrm{a}}$ can be linked to an appreciable decrease in the adsorption of the molecules of inhibitor on metallic surface with an increase in temperature [31].

Table 4. Electrochemical parameters for mild steel in $1.0 \mathrm{M} \mathrm{HCl}$ in the absence and presence of $10^{-4} \mathrm{M}$ of ATP.

\begin{tabular}{|c|c|c|c|c|c|}
\hline & $\mathbf{T}(\mathrm{K})$ & $E_{\text {corr }}(\mathrm{mV} / \mathrm{Ag} / \mathrm{AgCl})$ & $i_{\text {corr }}\left(\mu \mathrm{A} / \mathbf{c m}^{2}\right)$ & $\beta_{\mathrm{c}}(\mathrm{mV} / \mathrm{dec})$ & $\eta_{p p}(\%)$ \\
\hline \multirow{4}{*}{ Blank Solution } & 298 & -498 & 467 & -170 & - \\
\hline & 308 & -491 & 800 & -178 & - \\
\hline & 318 & -475 & 1470 & -165 & - \\
\hline & 328 & -465 & 2000 & -151 & - \\
\hline \multirow{4}{*}{$10^{-4} \mathrm{M}$ of ATP } & 298 & -422 & 28 & -106 & 94.00 \\
\hline & 308 & -447 & 68 & -103 & 91.50 \\
\hline & 318 & -483 & 132 & -95 & 91.02 \\
\hline & 328 & -491 & 204 & -92 & 89.80 \\
\hline
\end{tabular}

However, the enthalpy $\left(\Delta \mathrm{H}_{\mathrm{a}}^{*}\right)$ and entropy $\left(\Delta \mathrm{S}_{\mathrm{a}}{ }_{\mathrm{a}}\right)$ of activation process were determined from transition state equation:

$$
\mathrm{i}_{\text {corr }}=\frac{\mathrm{RT}}{\mathrm{Nh}} \exp \left(\frac{\Delta \mathrm{S}_{\mathrm{a}}^{*}}{\mathrm{R}}\right) \exp \left(-\frac{\Delta \mathrm{H}_{\mathrm{a}}^{*}}{\mathrm{RT}}\right)
$$

where $\mathrm{h}$ and $\mathrm{N}$ represent the Planck constant and Avogadro number, respectively. 
Table 5. Activation parameters for mild steel corrosion in $1.0 \mathrm{M} \mathrm{HCl}$ in the absence and presence of different concentrations of ATP

\begin{tabular}{|c|c|c|c|c|}
\hline & $\mathrm{C}(\mathrm{M})$ & $\mathrm{E}_{\mathrm{a}}\left(\mathrm{kJ} \mathrm{mol}^{-1}\right)$ & $\Delta \mathrm{H}_{\mathrm{a}}^{*}\left(\mathrm{~kJ} \mathrm{~mol}^{-1}\right)$ & $\Delta \mathrm{S}_{\mathrm{a}}^{*}\left(\mathrm{~J} \mathrm{~mol}^{-1} \mathrm{~K}^{-1}\right)$ \\
\hline Blank Solution & 00 & 40.53 & 37.93 & -66.50 \\
\hline ATP & $\begin{array}{c}10^{-6} \\
10^{-5} \\
5 \times 10^{-5} \\
10^{-4} \\
10^{-3}\end{array}$ & $\begin{array}{l}50.32 \\
50.47 \\
52.46 \\
54.05 \\
50.62\end{array}$ & $\begin{array}{l}46.79 \\
47.87 \\
49.86 \\
51.45 \\
48.02\end{array}$ & $\begin{array}{l}-54.66 \\
-51.61 \\
-47.19 \\
-44.00 \\
-50.21\end{array}$ \\
\hline
\end{tabular}

The variation in $\mathrm{Ln}\left(\mathrm{i}_{\text {corr }} / \mathrm{T}\right)$ versus $1 / \mathrm{T}$ at different concentrations of ATP is presented in Fig. (9) showing straight lines. Their activation parameters are summarized in Table 5. It is revealed that all obtained $\Delta \mathrm{H}^{*}{ }_{\mathrm{a}}$ values for the dissolution reaction of mild steel in $1.0 \mathrm{M} \mathrm{HCl}$ in the presence of ATP are higher than that in its absence. In addition, the positive signs of $\Delta \mathrm{H}^{*}{ }_{\mathrm{a}}$ values reflect the endothermic nature of the mild steel dissolution process, recommending that its dissolution is lower in the presence of ATP. Additionally, it is shown that the obtained $\Delta \mathrm{S}^{*}$ a values increases with ATP addition compared to uninhibited solution signifying an increase in disorder during the corrosion process.

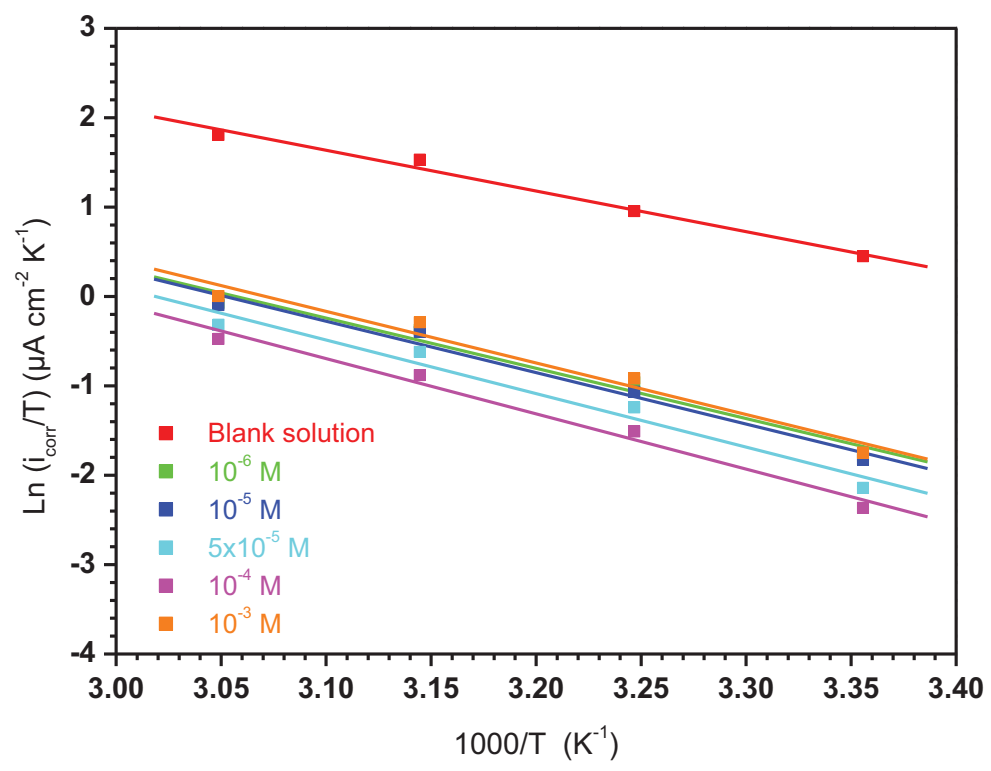

Fig. (9). Transition Arrhenius plots for mild steel in $1.0 \mathrm{M} \mathrm{HCl}$ solution in the absence and presence of different concentrations of ATP.

Table 6. Curve fitting results of ATP adsorption for different adsorption isotherms.

\begin{tabular}{|c|c|c|c|c|}
\hline Isotherms & Linear forms & Curves & Parameters & Values \\
\hline \multirow{3}{*}{ Langmuir } & \multirow{3}{*}{$\frac{\mathrm{C}_{\mathrm{inh}}}{\theta}=\frac{1}{\mathrm{~K}_{\mathrm{ads}}}+\mathrm{C}_{\mathrm{inh}}$} & \multirow{3}{*}{$\frac{\mathrm{C}_{\mathrm{inh}}}{\theta}=\mathrm{f}\left(\mathrm{C}_{\mathrm{inh}}\right)$} & $\mathrm{R}^{2}$ & 0.99996 \\
\hline & & & $\mathrm{K}_{\mathrm{ads}}\left(\mathrm{L} \mathrm{mol}^{-1}\right)$ & $2.05 \times 10^{6}$ \\
\hline & & & Slope & 1.06156 \\
\hline \multirow{4}{*}{ Freundlich } & \multirow{4}{*}{$\ln (\theta)=\ln \left(\mathrm{K}_{\mathrm{ads}}\right)+\frac{1}{\mathrm{n}} \ln \left(\mathrm{C}_{\mathrm{inh}}\right)$} & \multirow{4}{*}{$\ln (\theta)=f\left(\ln \left(C_{i n h}\right)\right)$} & $\mathrm{R}^{2}$ & 0.90623 \\
\hline & & & $\mathrm{K}_{\mathrm{ads}}\left(\mathrm{L} \mathrm{mol}^{-1}\right)$ & 1.06 \\
\hline & & & Slope $(1 / \mathrm{n})$ & 0.01384 \\
\hline & & & $\mathrm{n}$ & 72.25 \\
\hline \multirow{4}{*}{ Temkin } & \multirow{4}{*}{$\theta=\frac{1}{\mathrm{f}} \ln \left(\mathrm{K}_{\mathrm{ads}}\right)+\frac{1}{\mathrm{f}} \ln \left(\mathrm{C}_{\mathrm{inh}}\right)$} & \multirow{4}{*}{$\theta=\mathrm{f}\left(\ln \left(\mathrm{C}_{\mathrm{inh}}\right)\right)$} & $\mathrm{R}^{2}$ & 0.90543 \\
\hline & & & $\mathrm{K}_{\mathrm{ads}}\left(\mathrm{L} \mathrm{mol}^{-1}\right)$ & 83.33 \\
\hline & & & Pente $(1 / \mathrm{f})$ & 0.01258 \\
\hline & & & $\mathrm{A}$ & 79.49 \\
\hline
\end{tabular}


(Table $\square$ ) contd.....

\begin{tabular}{|c|c|c|c|c|}
\hline Isotherms & Linear forms & Curves & Parameters & Values \\
\hline \multirow{4}{*}{ Frumkin } & \multirow{4}{*}{$\ln \left(\mathrm{C}_{\mathrm{inh}} \times \frac{1-\theta}{\theta}\right)=-\ln \left(\mathrm{K}_{\mathrm{ads}}\right)-2 \mathrm{f} \theta$} & \multirow{4}{*}{$\ln \left(C_{\text {inh }} \times \frac{1-\theta}{\theta}\right)=f(\theta)$} & $\mathrm{R}^{2}$ & 0.86309 \\
\hline & & & $\mathrm{K}_{\mathrm{ads}}\left(\mathrm{L} \mathrm{mol}^{-1}\right)$ & $3.9 \times 10^{26}$ \\
\hline & & & Slope (-2f) & 52.60334 \\
\hline & & & $\mathrm{f}$ & -26.30 \\
\hline \multirow{3}{*}{ Flory-huggins } & \multirow{3}{*}{$\ln \left(\frac{\theta}{\mathrm{C}_{\mathrm{inh}}}\right)=\ln \left(\mathrm{K}_{\mathrm{ads}}\right)+\mathrm{a} \ln (1-\theta)$} & \multirow{3}{*}{$\ln \left(\frac{\theta}{C_{\text {inh }}}\right)=\ln (1-\theta)$} & $\mathrm{R}^{2}$ & 0.89258 \\
\hline & & & $\mathrm{K}_{\mathrm{ads}}\left(\mathrm{L} \mathrm{mol}^{-1}\right)$ & $3.9 \times 10^{10}$ \\
\hline & & & Slope (a) & 5.50857 \\
\hline
\end{tabular}

where $\mathrm{K}_{\mathrm{ads}}$ is the equilibrium constant of the adsorption process, $\mathrm{C}_{\mathrm{inh}}$ is the inhibitor concentration, $\mathrm{f}$ is the factor of energetic inhomogeneity and the parameter" $\mathrm{a}$ "is the water molecules number replaced by inhibitor molecules on metallic surface.

\subsection{Adsorption Isotherm}

In order to determine the interaction type between the inhibitor molecules and the metal surface, the adsorption isotherms models were used. For this, the surface coverage, $\theta$, for mild steel in $1.0 \mathrm{M} \mathrm{HCl}$ at different ATP concentrations was evaluated from current- potential curves. So, the Langmuir, Temkin, Frumkin, Freundlich and Flory-Huggins isotherms were made to fit the $\theta$ values at various concentrations of ATP. Their corresponding fitting parameters values are illustrated in Table 7. It has been found that the ATP molecules were adsorbed on the metallic surface according to the Langmuir isotherm model (Fig. 10).

Table 7. : Thermodynamic and kinetic parameters for the ATP adsorption on mild steel in $1.0 \mathrm{M} \mathrm{HCl}$ at different temperatures.

\begin{tabular}{|c|c|c|c|c|c|c|c|}
\hline Inhibitor & $\begin{array}{c}\mathbf{T} \\
\mathbf{( K )}\end{array}$ & $\mathbf{R}^{2}$ & Slope & $\begin{array}{c}\mathbf{K}_{\text {ads }} \\
\left(\mathbf{L ~ m o l}^{-1}\right)\end{array}$ & $\begin{array}{c}\Delta \mathbf{G}_{\text {ads }}^{*} \\
\left(\mathbf{k J ~ m o l}^{-1}\right)\end{array}$ & $\begin{array}{c}\Delta \mathbf{H}_{\text {ads }}^{*} \\
\left(\mathbf{k J ~ m o l}^{-1}\right)\end{array}$ & $\begin{array}{c}\Delta \mathbf{S}_{\text {ads }}^{*} \\
\left(\mathbf{J ~ m o l}^{-1} \mathbf{K}^{-1}\right)\end{array}$ \\
\hline & 298 & 0.9999 & 1.06 & 2399854 & -46.4 & -18.22 & \\
ATP & 308 & 0.9998 & 1.09 & 1641160 & -46.9 & & 94 \\
& 318 & 0.9998 & 1.09 & 1498232 & -48.2 & & \\
\hline
\end{tabular}

However, the free energy of adsorption $\left(\Delta \mathrm{G}^{*}{ }_{\text {add }}\right)$ can be determined using the following equation [32]:

$$
\mathrm{K}_{\mathrm{ads}}=\frac{1}{55.5} \exp \left(\frac{-\Delta \mathrm{G}_{\mathrm{ads}}^{*}}{\mathrm{RT}}\right)
$$

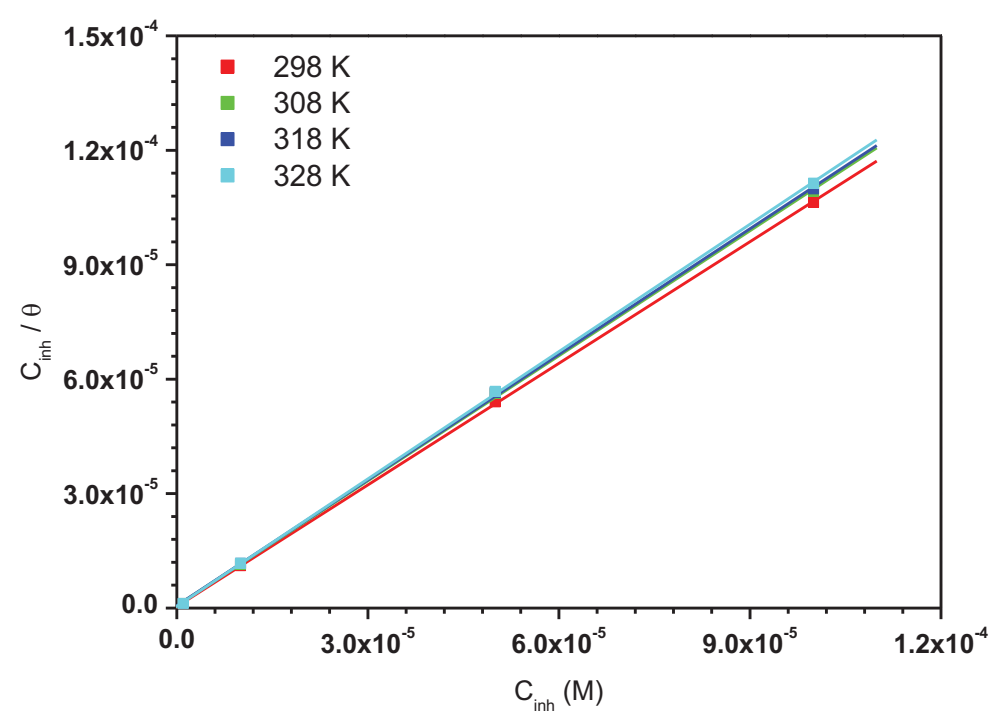

Fig. (10). Langmuir adsorption isotherm for mild steel in $1.0 \mathrm{M} \mathrm{HCl}$ in the presence of various concentrations of ATP at $298 \mathrm{~K}$.

where R, T, 55.5 represent the gas constant, the absolute temperature and the concentration of water in solution in mol L ${ }^{-1}$, respectively 
In addition, the enthalpy $\left(\Delta \mathrm{H}^{*}{ }_{\text {ads }}\right)$ and entropy $\left(\Delta \mathrm{S}^{*}{ }_{\text {ads }}\right)$ of adsorption can be obtained as follows [33]:

$$
\begin{gathered}
\Delta G_{a d s}^{*}=\Delta H_{a d s}^{*}-T \Delta S_{a d s}^{*} \\
\operatorname{Ln} K_{a d s}=-\frac{\Delta H_{a d s}^{*}}{R T}+\frac{\Delta S_{a d s}^{*}}{R}-\operatorname{Ln}(55.5)
\end{gathered}
$$

The variation in $\mathrm{Ln}\left(\mathrm{K}_{\mathrm{ads}}\right)$ versus $1 / \mathrm{T}$ is represented in Fig. (11) and the obtained thermodynamic adsorption parameters such as $\mathrm{K}_{\mathrm{ads}}, \Delta \mathrm{G}_{\mathrm{ads}}^{*}, \Delta \mathrm{H}_{\text {ads }}^{*}, \Delta \mathrm{S}_{\text {ads }}^{*}$ are illustrated in (Table 8).

It was found that $\Delta \mathrm{G}^{*}{ }_{\text {ads }}$ values are negative indicating the spontaneity of the adsorption of the inhibitor molecules on the metallic surface $[34,35]$ and the tough interaction between the ATP molecules and the mild steel surface [36, 37]. According to the literature, the adsorption type is regarded as physisorption when the value of $\Delta \mathrm{G}^{*}$ ads was found in the order of $-20 \mathrm{~kJ} \mathrm{~mol}^{-1}$ or lower while the chemisorptions are observed when the value of $\Delta \mathrm{G}^{*}{ }_{\text {ads }}$ is in the order of -40 $\mathrm{kJ} \mathrm{mol}^{-1}$ or higher [38 - 40]. In our case, the calculated $\Delta \mathrm{G}^{*}{ }_{\text {ads }}$ values Table 8 indicated that the adsorption mechanism of ATP on mild steel surface is typical of chemisorption. The same conclusion was found in our previous study, when we studied the interaction between hydroxyapatite molecules and mild steel in $1.0 \mathrm{M} \mathrm{HCl} \mathrm{[9].}$

On the other hand, the obtained negative sign of $\Delta \mathrm{H}^{*}$ ads indicated that the ATP molecules' adsorption is an exothermic process designing its physisorption or chemisorption [41]. In addition, the obtained $\Delta \mathrm{S}^{*}$ ads value in the presence of ATP was large and positive, showing high disordering that took places in going from reactants to the metal adsorbed species reaction complex. It was noted also that the value of the adsorption constant $\mathrm{K}_{\mathrm{ads}}$ decreased with temperature, demonstrating that the interactions between the adsorbed molecules and the metal surface were interrupted and, consequently, they became easily removable.

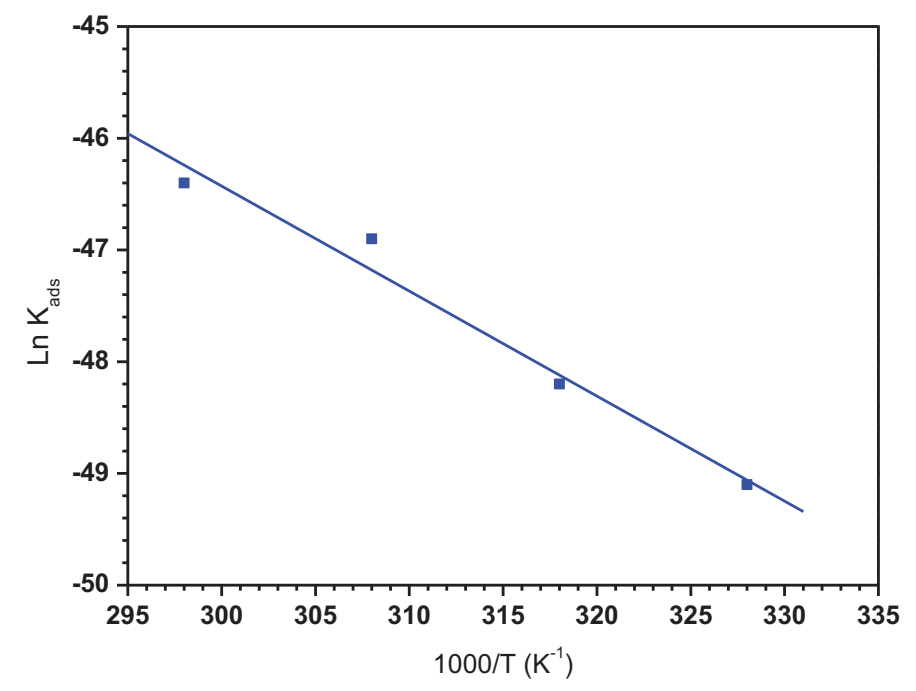

Fig. (11). The relationship between Ln (Kads) and 1000/T for ATP.

\subsection{Immersion Time Effect}

Fig. (12) shows the impedance diagrams for mild steel in $1.0 \mathrm{M} \mathrm{HCl}$ in the presence of $10^{-4} \mathrm{M}$ of ATP at different immersion times. It has been noted that all diagrams were composed of one capacitive loop where their diameter increased with immersion time until 4 hours and decreased after this time. The same circuit employed for the concentration effect was used to extract the electrochemical parameters which are presented in (Table 8).

However, it would be better to evaluate the inhibitor's temporal behavior through the kinetics associated to relatively long immersion times. From Table 8, it can be observd that the $\mathrm{R}_{\mathrm{ct}}$ increases with immersion time to reach a maximum of $96 \%$ at 4 hours in parallel with the decrease of $\mathrm{C}_{\mathrm{dl}}$ values. This evolution of $\mathrm{R}_{\mathrm{ct}}$ and $\mathrm{C}_{\mathrm{d} 1}$ was due mainly to the displacement of water molecules by $\mathrm{Cl}^{-}$ions of the acid and the adsorption of the inhibitor molecules on the metallic surface, decreasing the dissolution rate of the iron and $\mathrm{H}^{+}$proton reduction. After 4 hours of immersion, an increase in $\mathrm{C}_{\mathrm{dl}}$ values and a decrease in $\mathrm{R}_{\mathrm{ct}}$ values were observed. This can be explained by desorption of the ATP molecules from 
the mild steel surface.

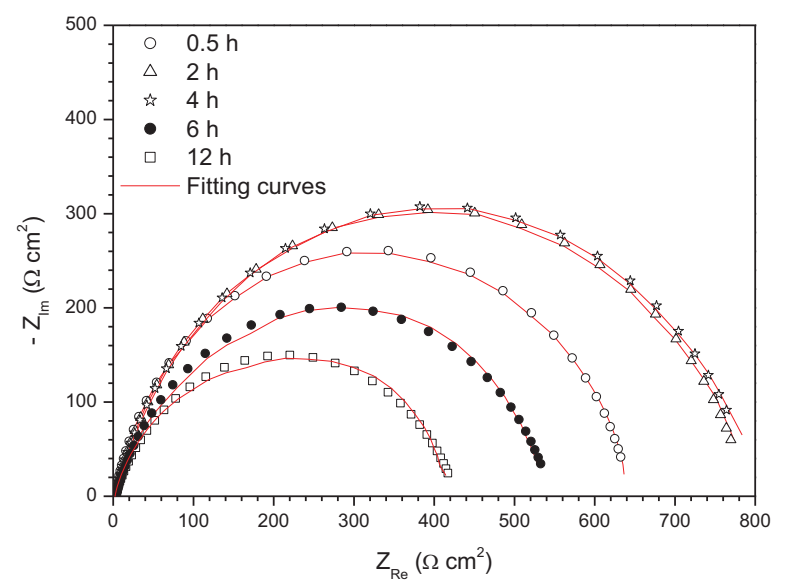

Fig. (12). Nyquist plots spectra for mild steel in $1.0 \mathrm{M} \mathrm{HCl}$ in the presence of 10-4 M of ATP at different immersion time.

Table 8. Electrochemical impedance parameters for carbon steel immerged in $1.0 \mathrm{M} \mathrm{HCl}$ with and without $10^{-4} \mathrm{M}$ of $\mathrm{ATP}$ at different immersion times.

\begin{tabular}{|c|c|c|c|c|c|c|}
\hline Immersion Time (h) & $\mathbf{R}_{\mathbf{s}}\left(\mathbf{\Omega} \mathbf{~ c m}^{2}\right)$ & $\mathbf{R}_{\mathrm{ct}}\left(\mathbf{\Omega} \mathbf{~ c m}^{\mathbf{2}}\right)$ & $\mathbf{C}_{\mathrm{dl}}\left(\boldsymbol{\mu} \mathbf{F} \mathbf{~ c m}^{-2}\right)$ & $\mathbf{n}_{\mathrm{ct}}$ & $\boldsymbol{\tau}_{\mathrm{dl}}(\mathbf{m s})$ & $\boldsymbol{\eta}_{\mathrm{EII}} \mathbf{( \% )}$ \\
\hline 0.5 & $2.03 \pm 0.19$ & $642.00 \pm 0.28$ & $45.04 \pm 0.68$ & $0.91 \pm 0.01$ & $28.91 \pm 0.001$ & 93.79 \\
\hline 2 & $2.18 \pm 0.20$ & $788.3 \pm 0.18$ & $44.39 \pm 0.68$ & $0.92 \pm 0.01$ & $34.99 \pm 0.001$ & 94.94 \\
\hline 4 & $2.86 \pm 0.19$ & $797.3 \pm 0.62$ & $43.02 \pm 0.67$ & $0.92 \pm 0.01$ & $34.30 \pm 0.001$ & 95.00 \\
\hline 6 & $2.91 \pm 0.19$ & $542.8 \pm 0.37$ & $87.00 \pm 1.26$ & $0.81 \pm 0.01$ & $47.22 \pm 0.001$ & 92.65 \\
\hline 12 & $2.01 \pm 0.21$ & $425.5 \pm 0.44$ & $88.80 \pm 1.93$ & $0.78 \pm 0.01$ & $37.78 \pm 0.001$ & 90.63 \\
\hline
\end{tabular}

\subsection{SEM Characterization}

The surface morphology observation of the mild steel before and after immersion in aggressive solution without and with $10^{-4} \mathrm{M}$ of ATP after 24 hours of immersion is presented in Fig. (13). Before immersion, it was observed that the surface was smooth and there was polishing scratch Fig. (13a). It is clear that the surface of mild steel without inhibitor was attacked (Fig. 13b)). The presence of cracks, pitting and corrosion products was also noted Fig. (13b). By contrast, on the mild steel surface obtained in the presence of $10^{-4} \mathrm{M}$ of ATP, this corrosion process did not initiate, as the surface was more regular, no porous with the appearance of white clusters which can be attributed to the phosphorus deposit on the mild steel surface Fig. (13c). This finding confirmed those obtained by the electrochemical measurements.
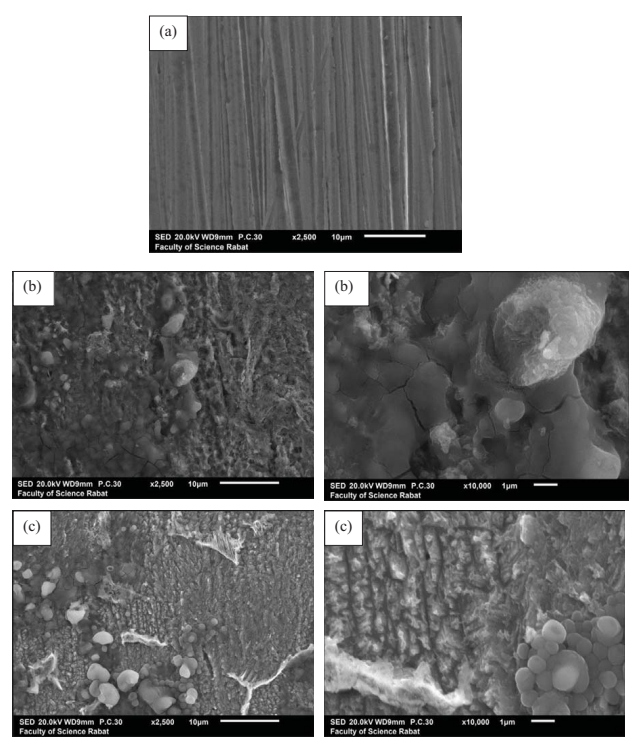

Fig. (13). SEM micrographs of mild steel (a) before immersion (b) in the absence (c) and presence of 10-4 M of ATP. 


\section{CONCLUSION}

The influence of anhydrous tricalcium phosphate on the corrosion behavior of mild steel in $1.0 \mathrm{M} \mathrm{HCl}$ by using the different electrochemical method was analysed, and it was found that:

1. The ATP reacts as a good inhibitor for mild steel corrosion in $1.0 \mathrm{M} \mathrm{HCl}$ and decreases both anodic and cathodic reactions.

2. The inhibition efficiency increases with the ATP concentrations to attain a maximum value of $94 \%$ at $10^{-4} \mathrm{M}$.

3. The current intensity-potential curves indicated that the ATP acts as a mixed type inhibitor.

4. The inhibition efficiency of ATP decreases slightly with temperature as well as immersion time after $4 \mathrm{~h}$.

5. The adsorption of ATP follows Langmuir's adsorption isotherm and it is chemical adsorption.

6. SEM analysis indicated that the ATP compound acts by the formation of a protective film on the mild steel surface.

\section{CONSENT FOR PUBLICATION}

Not applicable.

\section{CONFLICT OF INTEREST}

The authors declare no conflict of interest, financial or otherwise.

\section{ACKNOWLEDGEMENTS}

Declared none.

\section{REFERENCES}

[1] Bentiss F, Bouanis M, Mernari B, Traisnel M, Vezin H, Lagrenée M. Understanding the adsorption of 4H-1, 2, 4-triazole derivatives on mild steel surface in molar hydrochloric acid. Appl Surf Sci 2007; 253: 3696-704. [http://dx.doi.org/10.1016/j.apsusc.2006.08.001]

[2] Amin MA, Abd El-Rehim SS, El-Sherbini EEF, Bayyomi RS. The inhibition of low carbon steel corrosion in hydrochloric acid solutions by succinic acid: Part I. Weight loss, polarization, EIS, PZC, EDX and SEM studies. Electrochim Acta 2007; 52: 3588-600. [http://dx.doi.org/10.1016/j.electacta.2006.10.019]

[3] Tazouti A, Galai M, Touir R, et al. Experimental and theoretical studies for mild steel corrosion inhibition in $1.0 \mathrm{M}$ HCl by three new quinoxalinone derivatives. J Mol Liq 2016; 221: 815-32. [http://dx.doi.org/10.1016/j.molliq.2016.03.083]

[4] Alaoui K, El Kacimi Y, Galai M, et al. Poly (1-phenylethene): As a Novel Corrosion Inhibitor for Carbon Steel/Hydrochloric Acid Interface. Anal Bioanal Electrochem 2016; 8: 830-47.

[5] Labriti B, Dkhireche N, Touir R, et al. Synergism in Mild Steel Corrosion and Scale Inhibition by a New Oxazoline in Synthetic Cooling Water. Arab J Sci Eng 2012; 37: 1293-303. [http://dx.doi.org/10.1007/s13369-012-0257-7]

[6] Afrine L, Zarrouk A, Zarrok H, et al. Gravimetric and electrochemical impedance spectroscopy study for 4-(2- chlorobenzyl)-6-hydrazino-3methyl-1,6-dihydropyridazine as inhibitor corrosion for copper in nitric acid. J Chem Pharm Res 2013; 5: $1474-81$.

[7] Abboud Y, Abourriche A, Saffaj T, et al. 2, 3-Quinoxalinedione as a novel corrosion inhibitor for mild steel in 1M HCl. Mater Chem Phys 2007; 105: 1-5.

[http://dx.doi.org/10.1016/j.matchemphys.2007.03.037]

[8] El Hezzat M, Assouag H, Benzekri Z, et al. Der Pharma Chemica 2015; 7 : 77-88.

[9] Chafki L, Galai M, Rifi E-H, et al. Corrosion inhibition of mild steel in 1 M HCl Solution by hydroxyapatite. J Chem Pharm Res 2015; 7: 44-53.

[10] Galai M, El Gouri M, Dagdag O, El Kacimi Y, Elharfi A, Ebn Touhami M. New Hexa Propylene Glycol Cyclotiphosphazene As Efficient Organic Inhibitor of Carbon Steel Corrosion in Hydrochloric Acid Medium. J Mater Environ Sci 2016; 7: $1562-75$.

[11] Aboia OK, James AO. The effects of Aloe vera extract on corrosion and kinetics of corrosion process of zinc in HCl solution. Corros Sci 2010; 52: 661-4. [http://dx.doi.org/10.1016/j.corsci.2009.10.026]

[12] Eddy NO, Odoemelam SA. Inhibition of corrosion of mild steel in acidic medium using ethanol extract of Aloe vera. Pigm Resin Technol 2009; 38: 111-5. [http://dx.doi.org/10.1108/03699420910940617] 
[13] Szyprowski AJ. Relationship between chemical structure of imidazoline inhibitors and their effectiveness against hydrogen sulphide corrosion of steels. Br Corros J 2000; 35: 155-60. [http://dx.doi.org/10.1179/000705900101501209]

[14] Granese SL, Rosales BM, Oviedo C, Zerbino JO. The inhibition action of heterocyclic nitrogen organic compounds on Fe and steel in HCl media. Corros Sci 1992; 33: 1439-53. [http://dx.doi.org/10.1016/0010-938X(92)90182-3]

[15] Abdallah M, El Defrawy AM, Zaafarany IA, Sobhi M, Elwahy AHM, Shaaban MR. Corrosion inhibition of carbon steel in sulphuric acid solutions by novel bisaminothiazole derivatives: chemical, electrochemical and DFT Studies. Int J Electrochem Sci 2014 ; 9: $2186-207$.

[16] Ai JZ, Guo XP, Qu JE, Chen ZY, Zheng JS. Adsorption behavior and synergistic mechanism of a cationic inhibitor and KI on the galvanic electrode. Colloids Surf A Physicochem Eng Asp 2006; 281: 147-55. [http://dx.doi.org/10.1016/j.colsurfa.2006.02.031]

[17] Quartarone G, Bonaldo L, Tortato C. Inhibitive action of indole-5-carboxylic acid towards corrosion of mild steel in deaerated 0.5 M sulfuric acid solutions. Appl Surf Sci 2006; 252: 8251-7. [http://dx.doi.org/10.1016/j.apsusc.2005.10.051]

[18] Tamil Selvi S, Raman V, Rajendran N. Corrosion inhibition of mild steel by benzotriazole derivatives in acidic medium. J Appl Electrochem 2003; 33: 1175 . [http://dx.doi.org/10.1023/B:JACH.0000003852.38068.3f]

[19] Chauhan LR, Gunasekaran G. Corrosion inhibition of mild steel by plant extract in dilute HCl medium. Corros Sci 2007; 49 : $1143-61$. [http://dx.doi.org/10.1016/j.corsci.2006.08.012]

[20] Touir R, Cenoui M, El Bakri M, Ebn Touhami M. Sodium gluconate as corrosion and scale inhibitor of ordinary steel in simulated cooling water. Corros Sci 2008; 50: 1530-7.

[http://dx.doi.org/10.1016/j.corsci.2008.02.011]

[21] Gerengi H, Darowicki K, Bereket G, Slepski P. Evaluation of corrosion inhibition of brass-118 in artificial seawater by benzotriazole using Dynamic EIS. Corros Sci 2009; 51: 2573-9.

[http://dx.doi.org/10.1016/j.corsci.2009.06.040]

[22] Brug GJ, Van Den Eeden ALG, Sluyters-Rehbach M, Sluyters JH. The analysis of electrode impedances complicated by the presence of a constant phase element. J Electroanal Chem 1984; 176: 275-95. [http://dx.doi.org/10.1016/S0022-0728(84)80324-1]

[23] Maradi M, Duan J, Du X. Investigation of the effect of 4, 5-dichloro-2-n-octyl-4-isothiazolin-3-one inhibition on the corrosion of carbon steel in Bacillus sp. inoculated artificial seawater. Corros Sci 2013; 69: 338-45. [http://dx.doi.org/10.1016/j.corsci.2012.12.017]

[24] Tang Y, Zhang F, Huc S, Cao Z, Wu Z, Jing W. Novel benzimidazole derivatives as corrosion inhibitors of mild steel in the acidic media. Part I: Gravimetric, electrochemical, SEM and XPS studies. Corros Sci 2013; 74: 271-82. [http://dx.doi.org/10.1016/j.corsci.2013.04.053]

[25] Popova A, Christov M, Vasilev A. Mono-and dicationic benzothiazolic quaternary ammonium bromides as mild steel corrosion inhibitors. Part II: Electrochemical impedance and polarisation resistance results. Corros Sci 2011; 53: 1770-7. [http://dx.doi.org/10.1016/j.corsci.2011.01.055]

[26] Khaled KF, Al-Qahtani MM. The inhibitive effect of some tetrazole derivatives towards Al corrosion in acid solution: Chemical, electrochemical and theoretical studies. Mater Chem Phys 2009; 113: 150-8. [http://dx.doi.org/10.1016/j.matchemphys.2008.07.060]

[27] Abdel-Gaber M, Abd-El-Nabey B-A, Sidahmed IM, El-Zayaday AM, Saadawy M. Inhibitive action of some plant extracts on the corrosion of steel in acidic media. Corros Sci 2006; 48: 2765-79. [http://dx.doi.org/10.1016/j.corsci.2005.09.017]

[28] Ammar IA, El Khorafi FM. Adsorbability of thiourea on iron cathodes. Materials and Corrosion 1973; 24: 702-7. [http://dx.doi.org/10.1002/maco.19730240806]

[29] Bouklah M, Hammouti B, Lagrenee M, Bentiss F. Thermodynamic properties of 2,5-bis(4-methoxyphenyl)-1,3,4-oxadiazole as a corrosion inhibitor for mild steel in normal sulfuric acid medium. Corros Sci 2006; 48: 2831-42. [http://dx.doi.org/10.1016/j.corsci.2005.08.019]

[30] Popova A, Sokolova E, Raicheva S. Christov M. AC and DC study of the temperature effect on mild steel corrosion in acid media in the presence of benzimidazole derivatives. Corros Sci 2003; 45: 33-58 [http://dx.doi.org/10.1016/S0010-938X(02)00072-0]

[31] Szauer T, Brand A. Adsorption of oleates of various amines on iron in acidic solution. Electrochim Acta 1981; 26: 1253-6. [http://dx.doi.org/10.1016/0013-4686(81)85107-9]

[32] Bentiss F, Lebrini M, Lagrenee M. Thermodynamic characterization of metal dissolution and inhibitor adsorption processes in mild steel/2,5bis(n-thienyl)-1,3,4- thiadiazoles/hydrochloric acid system. Corros Sci 2005; 47: 2915-31.

[http://dx.doi.org/10.1016/j.corsci.2005.05.034] 
[33] Badiea AM, Mohana KN. Effect of temperature and fluid velocity on corrosion mechanism of low carbon steel in presence of 2-hydrazino4,7- dimethylbenzothiazole in industrial water medium. Corros Sci 2009; 51: 2231-41. [http://dx.doi.org/10.1016/j.corsci.2009.06.011]

[34] Talati JD, Gandhi DK. N-heterocyclic compounds as corrosion inhibitors for aluminium-copper alloy in hydrochloric acid. Corros Sci 1983; 23: $1315-32$. [http://dx.doi.org/10.1016/0010-938X(83)90081-1]

[35] Osman MM, Shalaby MN. Some ethoxylated fatty acids as corrosion inhibitors for low carbon steel in formation water. Mater Chem Phys 2003; 77: 261-9.

[http://dx.doi.org/10.1016/S0254-0584(01)00580-6]

[36] Elachouri M, Hajji MS, Kertit S, Essassi EM, Salem M, Coudert R. Some surfactants in the series of 2-(alkyldimethylammonio) alkanol bromides as inhibitors of the corrosion of iron in acid chloride solution. Corros Sci 1995; 37: 381-9. [http://dx.doi.org/10.1016/0010-938X(94)00134-R]

[37] Savithri BV, Mayanna SM. Tetrabutyl ammonium iodide, cetyl pyridinium bromide and cetyl trimethyl ammonium bromide as corrosion inhibitors for mild steel in sulphuric acid. Ind J Chem Technol 1996; 3: 256-8.

[38] Szklarska-Smialowska Z, Mankowski J. Crevice corrosion of stainless steels in sodium chloride solution. Corros Sci 1978; 18 : 953-60. [http://dx.doi.org/10.1016/0010-938X(78)90030-6]

[39] Yurt A, Ulutas S, Dal H. Electrochemical and theoretical investigation on the corrosion of aluminium in acidic solution containing some Schiff bases. Appl Surf Sci 2006; 253: 919-25. [http://dx.doi.org/10.1016/j.apsusc.2006.01.026]

[40] Hongbo F. Synthesis and Application of New Type Inhibitors. Chemical Industry Press Beijing $2002 ; 166$.

[41] Durnie W, Marco RD, Jefferson A, Kinsella B. Development of a structure-activity relationship for oil field corrosion inhibitors. J Electrochem Soc 1999; 146: 1751-6.

[http://dx.doi.org/10.1149/1.1391837]

\section{(C) 2018 Chafki et al.}

This is an open access article distributed under the terms of the Creative Commons Attribution 4.0 International Public License (CC-BY 4.0), a copy of which is available at: (https://creativecommons.org/licenses/by/4.0/legalcode). This license permits unrestricted use, distribution, and reproduction in any medium, provided the original author and source are credited. 